\title{
KINEMATIC ANALYSIS EVOLUTION OF EXTENDED LANDSLIDES: TWO CASE STUDIES FROM WESTERN GREECE
}

\author{
Kavoura K. ${ }^{1}$, Anagnostopoulou S. ${ }^{1}$, Servou K. ${ }^{1}$, Depoundis N. ${ }^{1}$, \\ Nikolakopoulos K. ${ }^{1}$ and Sabatakakis N. ${ }^{1}$ \\ ${ }^{1}$ University of Patras, Department of Geology, 26504, Patras, Greece, kavoura@upatras.gr
}

\begin{abstract}
Two of the most well known historical landslide occurrences are analyzed and their temporal evolution is presented. The sites of Panagopoula and Karya are often referred as the most representative cases of long term ground displacements based on inclinometer monitoring data. Regarding these cases, the heavy rainfalls constitute the main controlling (triggering) factor, while flysch is the critical landslide-prone formation which significantly contributes to landsliding. The inclinometer data through a long time period were analyzed and typical movement diagrams were compiled. A simple statistical model including data normalization through several active stages (phases) of movement is used to identify the common kinematic features as well as to estimate the velocity trend type of movement.

Keywords: long term, inclinometer measurements, Panagopoula, Karya.
\end{abstract}

\section{Пєрí $\eta \psi \eta$}

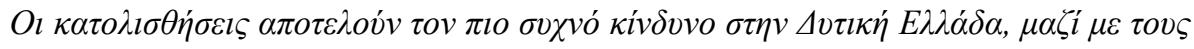

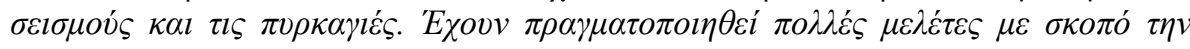

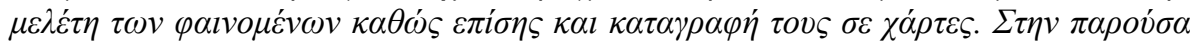

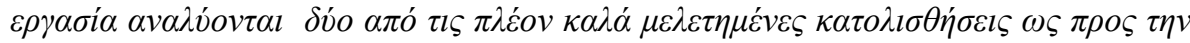

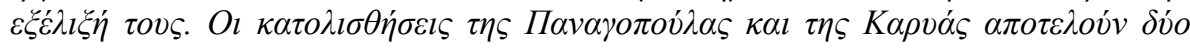

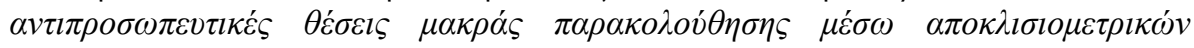

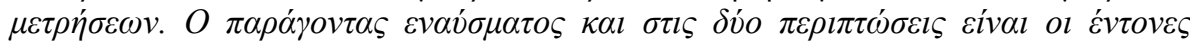

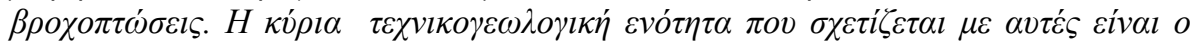

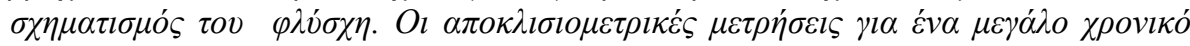

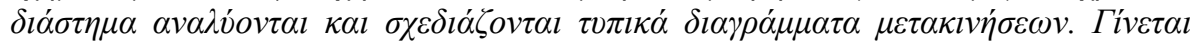

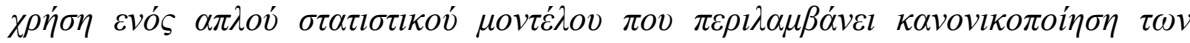

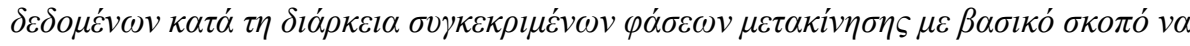

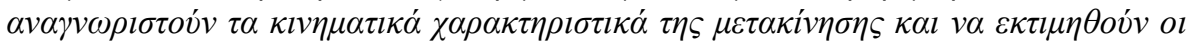

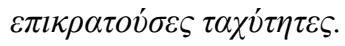

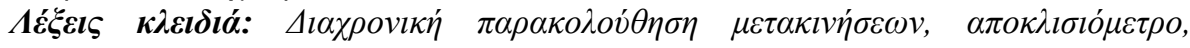

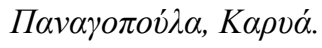

\section{Introduction}

It is widespread known that landslides constitute a major geological hazard that causes significant damages and both costs direct or indirect annually. The majority of landslides which suffer Greek territory usually affect only infrastructure and natural environment without human faculties. 
Moreover, local authorities and engineering companies involve a lot of geotechnical surveys to provide the best solution in order to avoid the failures. In some cases an extensive instrumentation program using inclinometers is enough to identify any shallow or deep movements. In this study two typical landslide cases that have been monitored with inclinometers were selected to establish displacement diagrams based on the long term data series. It is important to mention that both of them are classified as extremely slow-moving landslides both of them (WP/WLI, 1995). Historical data sets of inclinometers were used to evaluate the temporal evolution of movements. Moreover, a consistent dataset of continuous displacement measurements was available for each site for specific time periods, while "fill measurement gaps" were also exist for a long time (up to three years). A simple statistical model was applied to identify the kinematic features as well as to estimate the velocity trend type of movement through the time. The total studied time frame of kinematic evolution was ranged from about 20 years in Panagopoula (1995-2015) to 10 years in Karya (20052015).

\section{Case 1: Panagopoula landslide}

\subsection{Historical review}

In the late 60's the New National Road Patras - Corinth was constructed at Panagopoula site (K.S. $193+500)$ a resulting in a $50 \mathrm{~m}$ high, $1: 1$ inclined slope upwards. The first movements were detected before 1970's by the use of remote sensing methods and aerial photos interpretation.

Generally, the presence of highly tectonic and sheared - weathered formations of Alpine basement (flysch) in that area were resulted in periodically instability phenomena, triggered by heavy rainfall and seismic activity (Sabatakakis et al., 2015; Koukis et al., 2005, 2009).

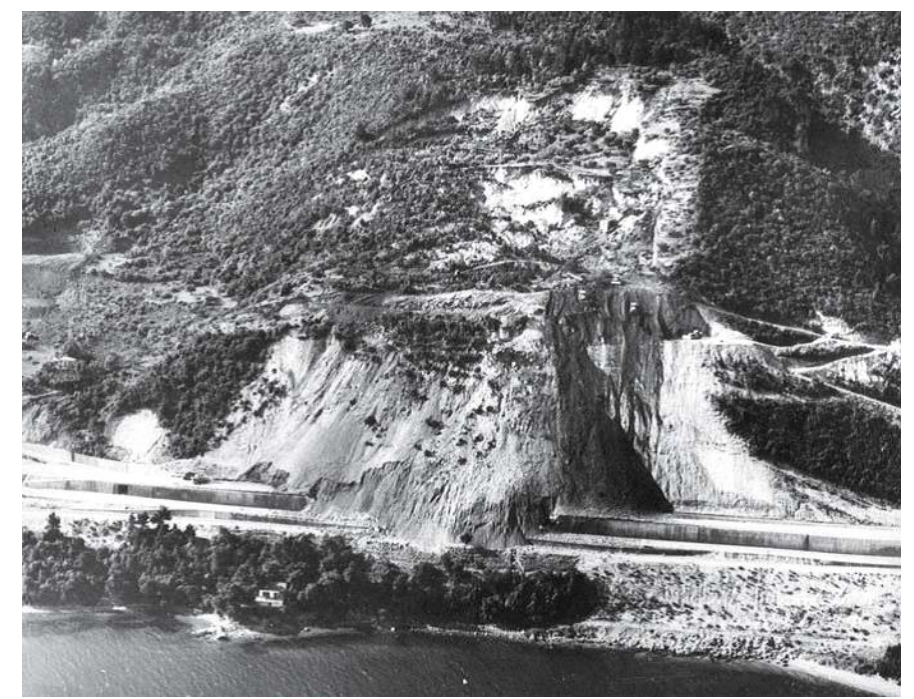

Figure 1 - Aerial photo of landslide taken on 28 April 1971.

On 25-26 April and 3 May 1971 large scale failures were recorded, (Andronopoulos, 1982). The landslide materials caused the interruption of traffic connection (old and new national road and railway line) for a long time. The transportation from and to western Greece was made only through the sea with the use of ferry boats for several months.

This large scale phenomenon evolved in two stages. A translational movement on structurally sheared and weathered flysch sediments on the upper part of the motorway slope failed over a zone of about $350 \mathrm{~m}$ that developed into a large volume earth flow in the lower part (Figure 1). The 
material was tectonically highly sheared and weathered flysch, while the volume of the dislocated debris was in excess of a million cubic meters. The slide depth was about $20 \mathrm{~m}$.

The second stage including an important rotational slide (May 1971) occurred in the adjacent area within the first stage debris flow and extended over a distance of about $250 \mathrm{~m}$. As a result severe cracks and failures in the New National road structures were recorded as well as damages up to the coastline (Figure 2). An important mass movement occurred in February 1972 in the weathered zone of the upper flattened slope. In view of these, numerous extensive geological and geotechnical investigations onshore as well as offshore took place in order to design the appropriate remedial measures. These included removal of debris material, slope flattening, two drainage tunnels (460 and $390 \mathrm{~m}$ long, constructed at $30 \mathrm{~m}$ and $95 \mathrm{~m}$ a.s.1 ), a network of drainage ditches, construction of retaining systems consisting mainly of gravity and cantilevered concrete walls.

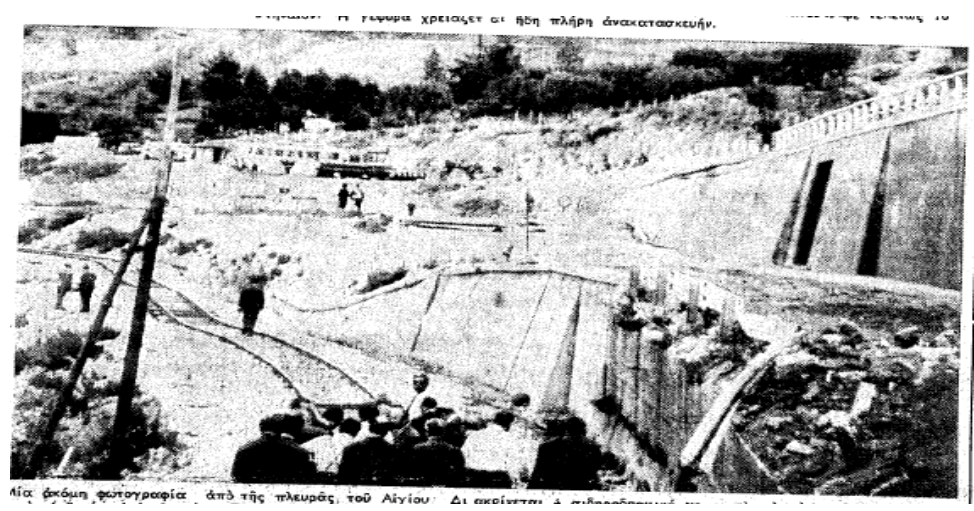

Figure 2 - Photograph published on press on 04/05/1971 from the suffered site.

The first inclinometer boreholes installed in February 1983 and November 1983 after the detected ruptures and cracks on the old national road pavement. During 1994 nineteen boreholes with piezometer and inclinometer were drilled (Figure 3) as part of a geotechnical investigation program. Monitoring indicated that the remedial works taken have been effective for the stabilization of the slope above the motorway, whereas horizontal displacements were still taking place downslope the highway. The final remedial measures were designed to stabilize the lower part of landslide zone included among others the construction of a pile wall with 20-25 m long piles and total length about $400 \mathrm{~m}$ which was constructed during 2001 to 2002 . Afterwards, the new high way and railway design included the construction of two tunnels by-passing the landsliding zone.

\subsection{Inclinometers survey}

A wide network of inclinometer boreholes have been installed along the years in the past and an abundance of measurements are available. Three main series measurements have been conducted. The first one took place during 1995 to 1997 and a second between 2002 and 2009. The third one done in the framework of LAVMO project, by the Laboratory of Engineering Geology of Patras University during the period March 2013 to June 2015 and it is goes on. 
Table 1 - A total catalogue of inclinometer boreholes which have been monitoring over years.

\begin{tabular}{|c|c|c|c|c|c|}
\hline Borehole & $\begin{array}{c}\text { Depth of } \\
\text { measurements }(\mathrm{m})\end{array}$ & \multicolumn{2}{|c|}{ Monitoring days } & \multicolumn{2}{|c|}{ Measured periods } \\
\hline D01 & 38 & \multicolumn{2}{|c|}{685} & \multicolumn{2}{|c|}{ 1995-1997 } \\
\hline D02 & 38 & \multicolumn{2}{|c|}{736} & \multicolumn{2}{|c|}{ 1995-1997 } \\
\hline D11 & 29 & \multicolumn{2}{|c|}{736} & \multicolumn{2}{|c|}{ 1995-1997 } \\
\hline D12 & 49 & \multicolumn{2}{|c|}{648} & \multicolumn{2}{|c|}{ 1995-1997 } \\
\hline D13 & 43 & \multicolumn{2}{|c|}{348} & \multicolumn{2}{|c|}{ 1995-1995 } \\
\hline D14 & 34 & \multicolumn{2}{|c|}{720} & \multicolumn{2}{|c|}{ 1995-1997 } \\
\hline D15 & 81 & \multicolumn{2}{|c|}{2146} & \multicolumn{2}{|c|}{ 1998-2004 } \\
\hline D21 & 49 & \multicolumn{2}{|c|}{832} & \multicolumn{2}{|c|}{ 1995-1997 } \\
\hline D22 & 35 & \multicolumn{2}{|c|}{347} & \multicolumn{2}{|c|}{ 1995-1995 } \\
\hline D23 & 44 & \multicolumn{2}{|c|}{848} & \multicolumn{2}{|c|}{ 1995-1997 } \\
\hline D24 & 37 & \multicolumn{2}{|c|}{848} & \multicolumn{2}{|c|}{ 1995-1997 } \\
\hline D25 & 38 & \multicolumn{2}{|c|}{637} & \multicolumn{2}{|c|}{ 1995-1997 } \\
\hline D26 & 39 & \multicolumn{2}{|c|}{797} & \multicolumn{2}{|c|}{ 1995-1997 } \\
\hline D31 & 49 & \multicolumn{2}{|c|}{579} & \multicolumn{2}{|c|}{ 1995-1996 } \\
\hline D32 & 69 & \multicolumn{2}{|c|}{767} & \multicolumn{2}{|c|}{ 1995-1997 } \\
\hline D34 & 38 & \multicolumn{2}{|c|}{297} & \multicolumn{2}{|c|}{ 1995-1995 } \\
\hline D35 & 29 & \multicolumn{2}{|c|}{578} & 199 & 1996 \\
\hline D35A & 49.5 & 2528 & 766 & $2002-2009$ & 2013-2015 \\
\hline D36 & 75 & 3970 & 494 & 1998-2009 & 2013-2015 \\
\hline D26A & 60 & & & 201 & 2015 \\
\hline D14A & 23 & & & 200 & 2009 \\
\hline G2 & 64 & & & 201 & 2015 \\
\hline
\end{tabular}

A new drilled inclinometer borehole (G2) installed on the western part of active part of landslide area and three pre-existing boreholes (D35A, D36 and D26A) closely located were start tracking again. As a result more extended time series achieved as shown on Table 1.

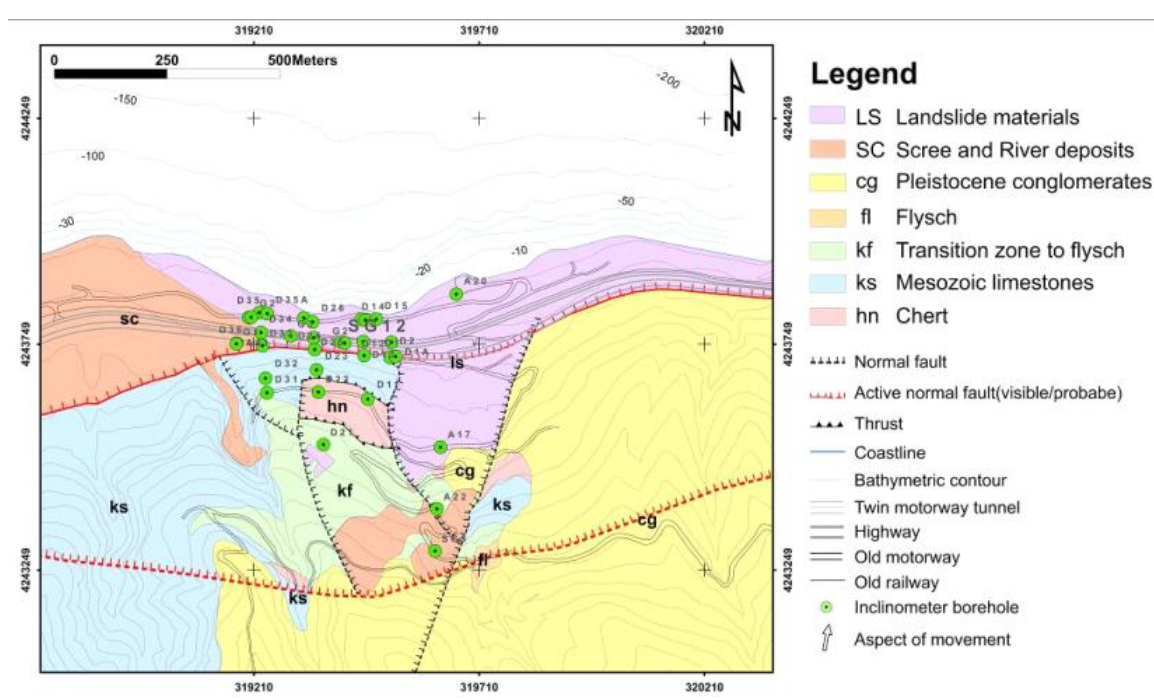

Figure 3 - Borehole positions on the simplified engineering-geological map of Panagopoula.

All these data were recorded and analyzed in order to display cumulative displacements versus time on charts. Two of them were characterized as long term monitoring boreholes (D35A and D36) as 
they have been monitored more than fifteen (15) years. Borehole D35A show a cumulative displacement up to $32 \mathrm{~mm}$ in $20 \mathrm{~m}$ depth for the period 2002-2009, while the borehole D36 about $54 \mathrm{~mm}$ in $25 \mathrm{~m}$ depth for the period 1998-2009 (Figure 4a).

Furthermore, measurements at the same boreholes showed $9.4 \mathrm{~mm}$ and $12.6 \mathrm{~mm}$ displacement respectively, for the period 4/2013-6/2015, while $9.87 \mathrm{~mm}$ displacement for the new drilled borehole G2 has also been measured for the same time period (Figure 4b). However, these time series does not consists a consistent data set of continuous measurements while there is a four year "gap of measurements" for the period 2009-2013. This is clearly shown in Figure 5, where displacement data coming from D36 were plotted in a chart and "a grey-zone in time series" has been revealed. The latest time series during the period 2013-2015 provides a monthly interval of measurements.

All these measurements give a remarkable data set in order to estimate the typical trends of displacement.

\subsection{Statistical analysis}

The available wide and long term archive of real inclinometer measurements permit to distinguish the velocity on critical stages on their evolution depending on the moving trends. For this purpose, a simple procedure which estimates the typical trends of displacements was used. According to this, the shorter the time between two consecutive monitoring data, the clearer the trend movement (Cascini et al., 2014). The best way to identify common kinematic features is by the normalization of cumulative displacement and time related on the duration of each activity stage of landslide. This formula is described as (Cascini et al., 2014):

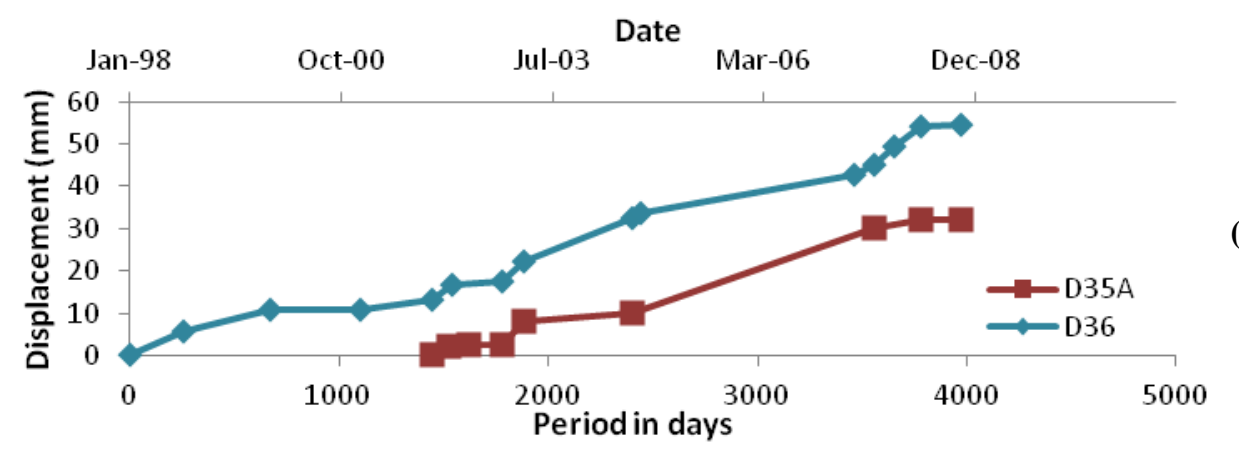

(a)

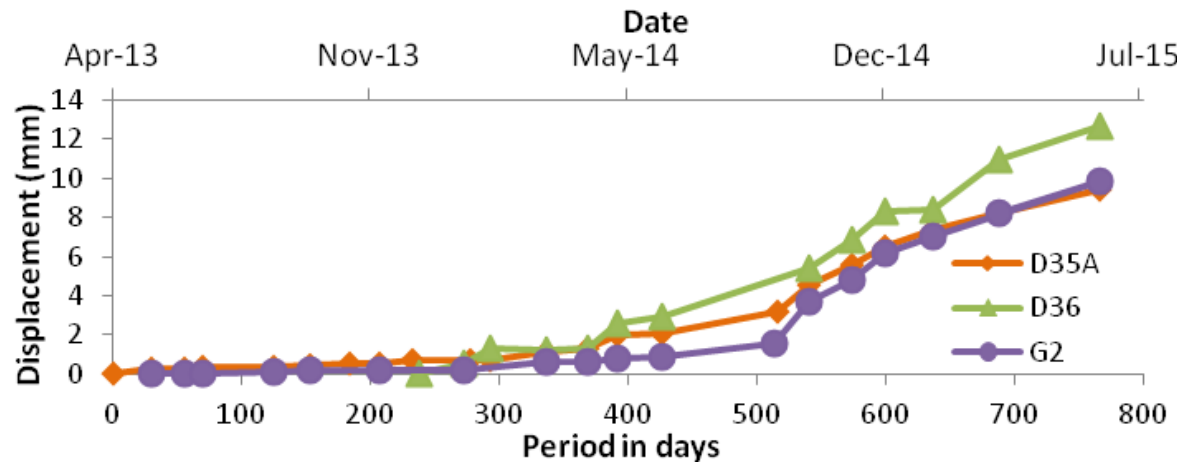

(b)

Figure 4 - Displacements calculated at the sliding surfaces a) displacements versus time for the period 1998-2009 b) displacements versus time for the period 2013-2015. 


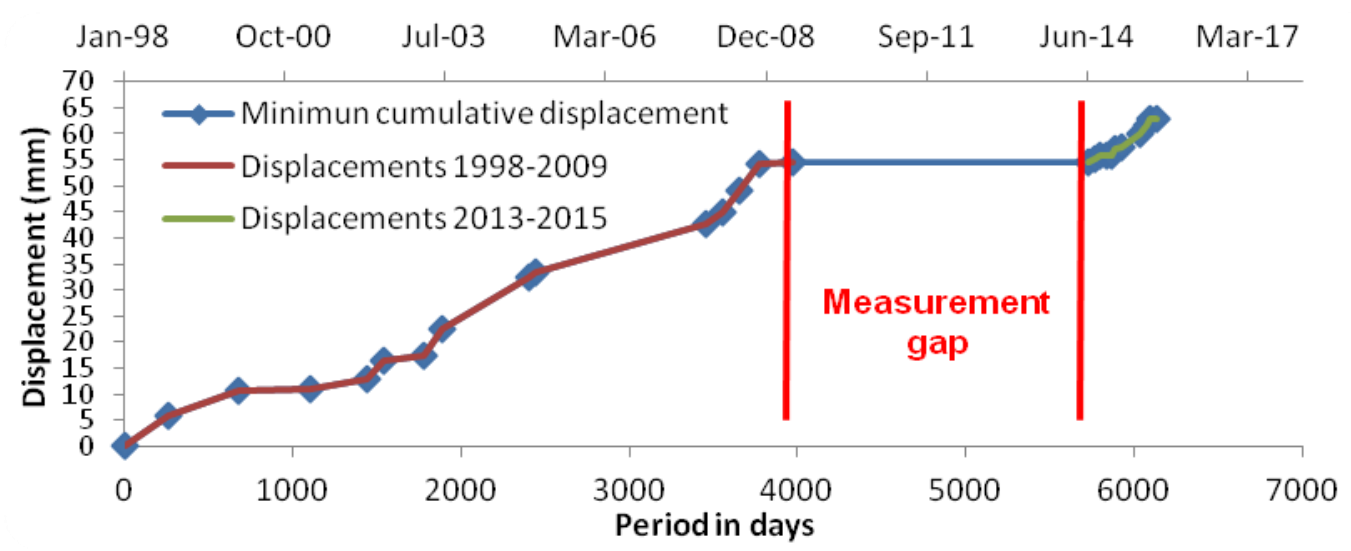

Figure 5 - Data set of D36 borehole present a "gap" from 2019-1013. Red line shows the cumulative displacement for the first period while the green line the second. The blue line represents the minimum cumulative displacement corresponding to zero displacement.

Equation 1 - Formulas for normalized displacements and time

$$
\begin{aligned}
& D_{i}\left(t_{j}\right)=\frac{d\left(t_{j}\right)-d_{\min , i}}{d_{\mathrm{max}, i}-d_{\mathrm{min}, i}} \\
& T_{i}\left(t_{j}\right)=\frac{t_{j}-t_{\mathrm{min}, i}}{t_{\mathrm{max}, i}-t_{\mathrm{min}, i}}
\end{aligned}
$$

where $d\left(t_{j}\right)$ is the monitored cumulative displacement at time $t_{j}, D_{i}\left(t_{j}\right)$ is the normalized dimensionless displacement at time $t_{j}, i$ is the active stage (phase), $d_{\min }$ and $d_{\max }$ are displacements at the beginning and end of active stage $i, T_{i}\left(t_{j}\right)$ is the normalized dimensionless time $t_{j}$ and $t_{\min }$ and $t_{\max }$ the time at the beginning and end of active stage. Inclination differences on the cumulative displacement curves determine individual active stages (i).

As shown Figure 6, four (4) active stages (phases) selected for testing the model of trends and calculate their individual velocities.

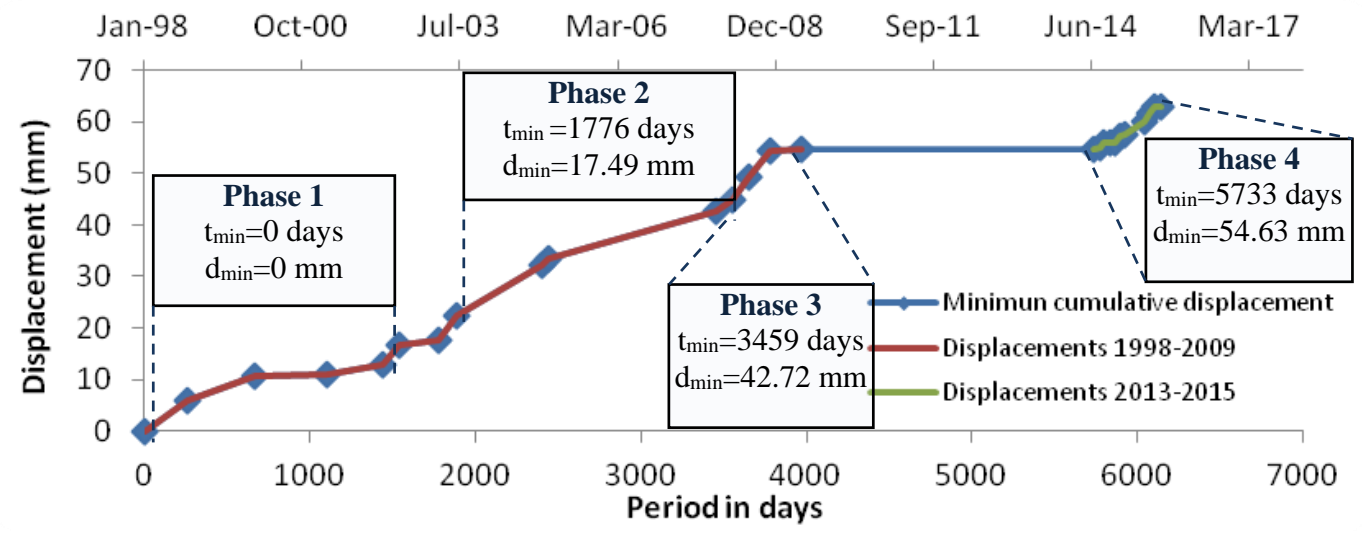

Figure 6 - Four active stages of displacements were detected on D36.

The framework for typical trends of displacements classifies the rate of movement into three trendtypes. Generally, all of them can describe through the equation below: 


\section{Equation 6 - Formula for trend expression}

$$
D_{i}\left(t_{j}\right)=T_{i}\left(t_{j}\right)^{x}
$$

The trend type-I $(x=1)$, refers on constant rate of movement, trend type II $(x<1)$ means that the rate of displacement decreases over the time and trend-type III $(x>1)$ correspond to accelerating movement. The trend type for each phase could be estimated after projecting on chart normalized cumulative displacements versus normalized time (Figure 7a). After the generation of such plot Phases 1 and 2 characterized as trend-type II, while the latest two periods of measurements, Phases 3 and 4, follow the trend type III. Consider the calculated velocities relevant to these Phases, arise that the latest period of movements 2013 to 2015 characterized by accelerating movements and the peak velocity is equal to $0.06 \mathrm{~mm} / \mathrm{d}$ (Figure $7 \mathrm{~b}$ ). The velocities of continuous displacements corresponding to each Phase are estimated by the following equation:

\section{Equation 7 - Formula for velocity expression}

$$
v(t)=\frac{\Delta d(t)}{\Delta t}
$$
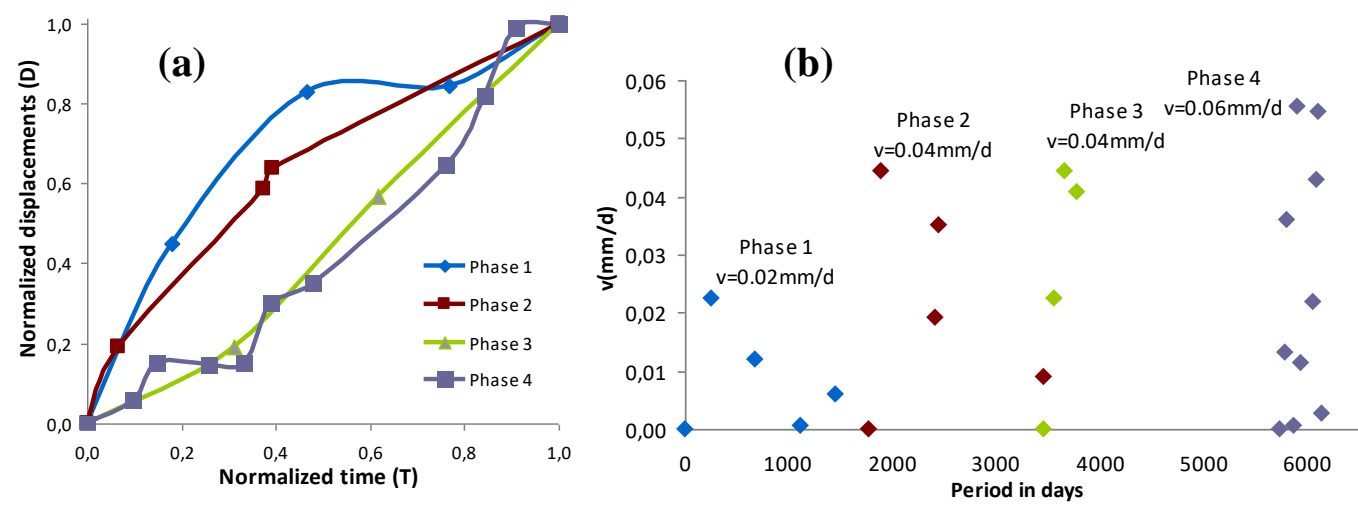

Figure 7 - (a) Trends of normalized displacements for each phase, (b) distribution of velocities on selected phases.

In February 1999, a sudden mass movement occurred during an intense and prolonged rainfall. The main road connecting nearby villages failed into a zone of $150 \mathrm{~m}$. The total length of landslide was about $500 \mathrm{~m}$ with a vertical movement of $35 \mathrm{~m}$ and a head width of $150 \mathrm{~m}$ (Figure $8 \mathrm{a}$ ).

In December 2001, after an intense rainfall (94.2 $\mathrm{mm}$ in less than $24 \mathrm{~h}$ ), a large volume of debris material failed suddenly, triggering a new extensive landslide which flowed rapidly on the westward side of the slope. A newly constructed house moved for about $50 \mathrm{~m}$ (Figure $8 \mathrm{~b}$ ) and destroyed by sliding masses totally, while the main road connecting the nearby villages also completely failed. The total volume of landslide materials since 1960' has been more than $600,000 \mathrm{~m}^{3}$ (Sabatakakis et al., 2005).

The geological settings involved the high folding and faulting features of alpine basement (flysch, limestone, chert). It was clear that the presence of the tectonic highly sheared and weathered flysch formation contributed to the periodically induced instability phenomena. These formations covered by the recent debris of Quaternary and landslide materials. Moreover, a number of geotechnical surveys which carried out in the past, note that the main surface of failure is in the contact of flysch with recent materials. 
The first inclinometer borehole set was installed in June 2003 and a second one was followed in November 2004. Recently, in March 2013 in the framework of LAVMO project a new inclinometer borehole was installed in main body of the landslide to replace the older boreholes.

\subsection{Inclinometers survey}

Karya landslide such as Panagopoula is characterized by a long term monitoring via inclinometer measurements. There are two main series of measurements which took place between the period 2003-2007 and 2013-2015. The second period was carried out in the framework of LAVMO project, by the Laboratory of Engineering Geology of Patras University during the period March 2013 to June 2015. The Table 2 summarizes these operations.

Table 2 - Inclinometer boreholes monitored over the last years.

\begin{tabular}{|c|c|c|c|}
\hline Borehole & $\begin{array}{c}\text { Depth of } \\
\text { measurements }(\mathbf{m})\end{array}$ & Monitoring days & Measured periods \\
\hline G1A & 48 & 1390 & $2003-2007$ \\
\hline G2A & 32.5 & 1608 & $2003-2007$ \\
\hline G3A & 45 & 1390 & $2003-2007$ \\
\hline G4A & 46.5 & 389 & $2003-2004$ \\
\hline G5A & 21.4 & 391 & $2003-2004$ \\
\hline G4 & 30 & 808 & $2013-2015$ \\
\hline
\end{tabular}

Date
$13 / 5 / 2003 \quad 8 / 3 / 2004$
$2 / 1 / 2005$
$29 / 10 / 2005 \quad 25 / 8 / 2006$
$21 / 6 / 2007 \quad 16 / 4 / 2008$

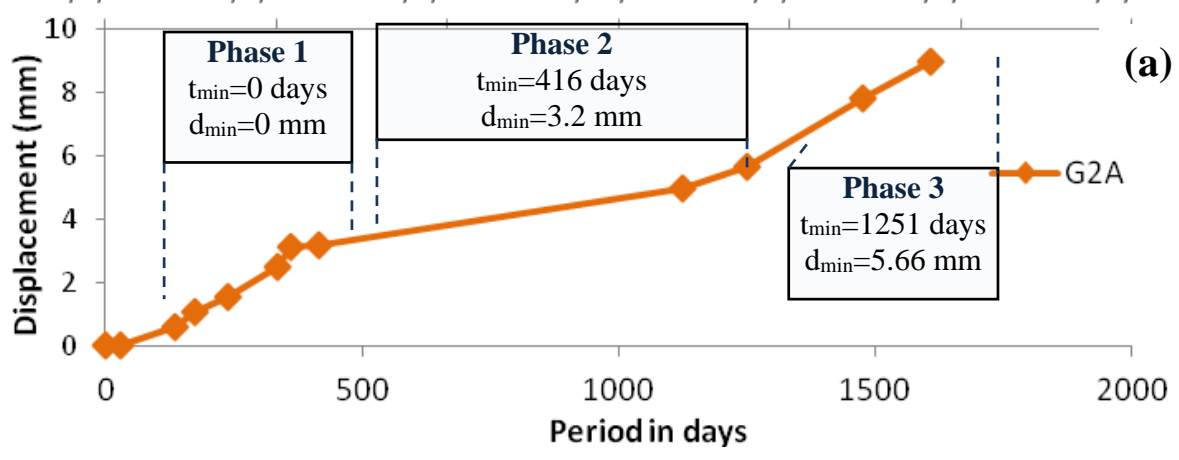

Date

$\begin{array}{lllllll}7 / 3 / 2013 & 4 / 8 / 2013 & 1 / 1 / 2014 & 31 / 5 / 2014 & 28 / 10 / 2014 & 27 / 3 / 2015 & 24 / 8 / 2015\end{array}$

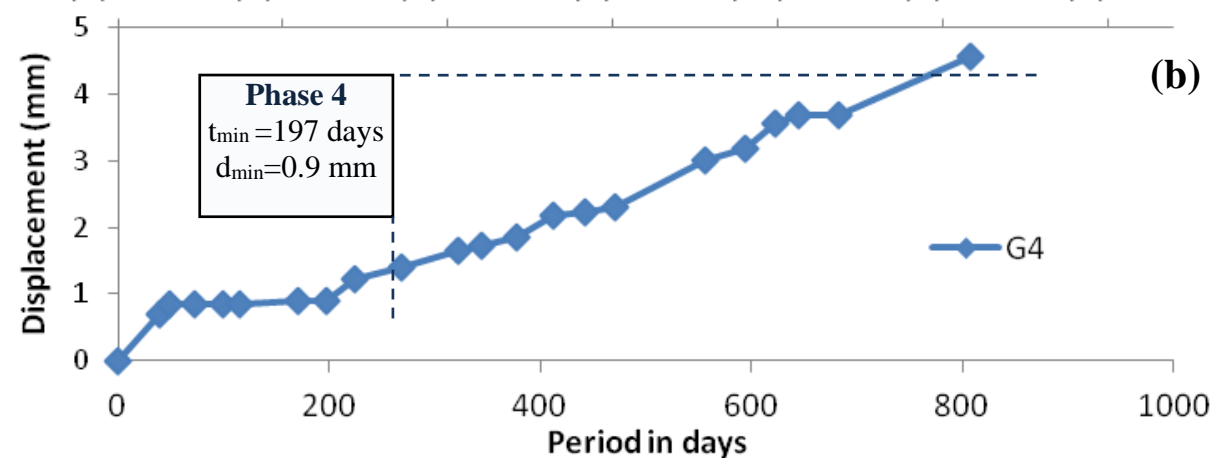

Figure 8 - Displacements detected on active boreholes (a) displacements of G2A for the period 2003-2007, (b) displacements of G4 for the period 2013-2015. 
Only in two boreholes (G2A and G4) significant displacements have been detected for the period 20032015. The G4 is located very close to G2A so it could be a helpful detector to validate the sliding surface as long as the moving evolution. As well, G2A had a cumulative displacement of the order of $9 \mathrm{~mm}$ in $19.5 \mathrm{~m}$ depth for the period 2003-2007 while G4, 4.5mm in $21 \mathrm{~m}$ depth for the period 2013-2015 (Figure 9).

\subsection{Statistical analysis}

Following the procedure presented above the typical trends of displacements for selected subperiods between to 2003-2007 were estimated. Four different phases were chosen to determine the kinematic behavior (Figure 9). As resulted from the plot of normalized cumulative displacements versus normalized time, the Phases 2, 3 and 4 characterized by the trend-type I, while the oldest Phase 1 characterized by the trend type III (Figure 10a). The maximum velocities relevant to the phases are extremely low with the highest noted on the Phase 1 with a value of order of $0.024 \mathrm{~mm} /$ day (Figure 10b). The main type of movement is linear.
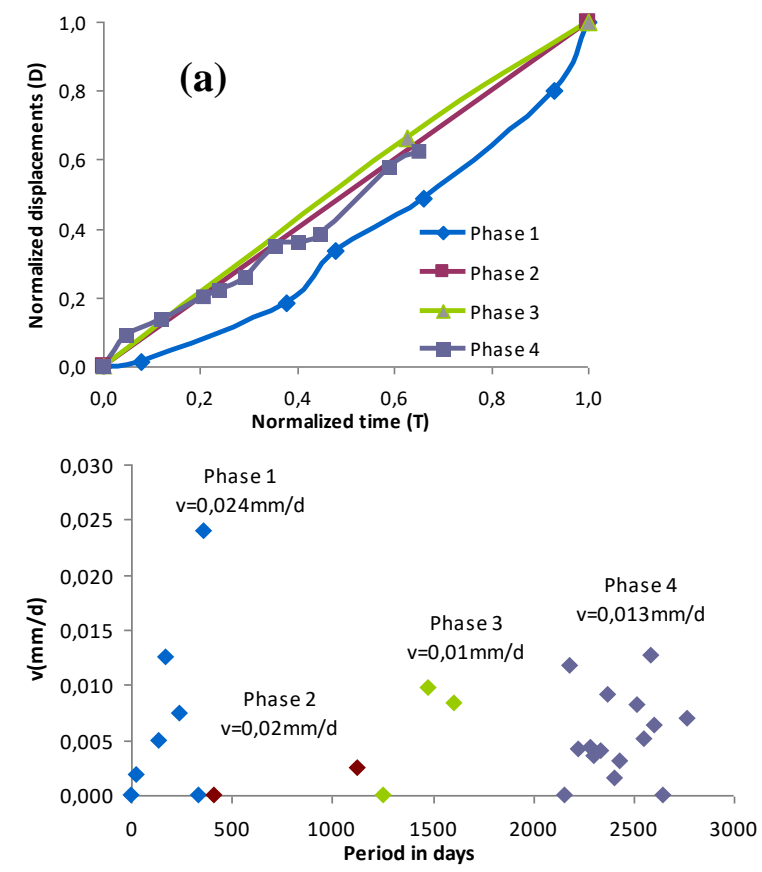

Figure 9 - (a) The typical trends of normalized displacements, (b) distribution of velocities on selected phases.

\section{Conclusions}

The landslide occurrences presented in this work are characterized by extremely low displacements. Long term measurements of displacements allow to recognize changes on the type of movement which could be linked with external dynamic factors such as earthquakes or heavy rainfalls. As resulted after the analysis of real displacements, the Panagopoula landslide appears significant changes on the kinematic behavior over the years with changing rate of movements between 0.02 and $0.06 \mathrm{~mm} /$ day. On the other hand Karya landslide notes obviously a constant rate of movement and very low velocities ( 0.01 to $0.025 \mathrm{~mm} /$ day). The correlation of the rate of movements with specific earthquakes and heavy rainfalls constitutes the next step of study for the influence of the triggering factors on the reactivation conditions. 


\section{Acknowledgments}

This research has been co-financed by the European Union (European Social Fund - ESF) and Greek national funds through the Operational Program "Education and Lifelong Learning" of the National Strategic Reference Framework (NSRF) - Research Funding Program: Thales. Investing in knowledge society through the European Social Fund.

\section{References}

Andronopoulos, B., 1982. The geological structure and the tectonic evolution as factors of instability in the Pindos zone area (Greece), Rock mechanics, 15(1): 41-54, doi: 10.1007/BF01239476.

Cascini, L., Calvello, M. and Grimaldi, G.M., 2014. Displacement trends of slow-moving landslides: classification and forecasting, Journal of Mountain Science, 11(3), 592-606.

Kavoura, K., Nikolakopoulos, K. and Sabatakakis, N., 2014. Relief evolution monitoring using airphotos time series and GIS. A case study from western Greece. EARSeL 34th Symposium Proceedings, ISBN 978-83-63245-65-8, (2), 19-26, doi: 10.12760/03-2014-03.

Koukis, G, Sabatakakis, N. and Lainas, S., 2007. Soil suitability for housing purposes in landslide-prone areas. The case of Karya village, Patras, W. Greece, Bull. Geol. Soc. Greece, XXXX/1, 1684-1694.

Koukis, G., Sabatakakis, N., Nikolaou, N. and Loupasakis, C., 2005. Landslide hazard zonation in Greece, Proceedings of the Open Symposium on landslide risk analysis and sustainable disaster management by International Consortium on Landslides, Washington, USA, 13 - 14 October 2005, Chapter 37, 291-296, doi: 10.1007/3-540-28680-2_37.

Koukis, G., Sabatakakis, N., Ferentinou, M., Lainas, S., Alexiadou, X. and Panagopoulos, A., 2009. Landslide phenomena related to major fault tectonics: rift zone of Corinth Gulf, Greece, Bull. Eng. Geol. Environ. 68, 215-229, doi: 10.1007/s10064-008-0184-8.

Sabatakakis, N., Koukis, G. and Mourtas, D., 2005. Composite landslides induced by heavy rainfalls in suburban areas: City of Patras and surrounding area, Western Greece, Landslides, 2(3), 202-211.

Sabatakakis, N., Tsiambaos, G., Rondoyanni, Th., Papanakli, S. and Kavoura, K., 2015. Deep-seated structurally controlled landslides of Corinth Gulf rift zone, Greece: the case of Panagopoula Landslide, 13th ISRM Congress Proceedings - Int'1 Symposium on Rock Mechanics - Innovations in Applied and Theoretical Rock Mechanics, ISBN: 978-1-926872-25-4, p651, 10p.

Tsiambaos, G., Sabatakakis, N., Rondoyanni, Th., Depoundis, N. and Kavoura, K., 2015. Composite landslides affecting flysch and Neogene weak rock formations induced by heavy rainfalls, 13th ISRM Congress Proceedings - Int'l Symposium on Rock Mechanics - Innovations in Applied and Theoretical Rock Mechanics, ISBN: 978-1-926872-25-4, p651, 10p.

WP/WLI, 1995. International Geotechnical Societies' UNESCO Working Party on World Landslide Inventory. Working Group on Rate of Movement (Chairman: Ch Bonnard). A suggested method for describing the rate of movement of a landslide, Bull Eng Geol Environ, 52, 75-78. 